\title{
Comfort Driven Redesign Methods: An Application to Mattresses Production Systems
}

\author{
M. Vallone, A. Naddeo*, N. Cappetti and R. Califano
}

Department of Industrial Engineering, University of Salerno, Salerno, Italy

\begin{abstract}
The definitions of methods and tools used to evaluate how workers perceive the comfort during their activities remains an "open" problem at this time. Many researchers have dealt with that problem in the last twenty years, focusing their efforts primarily on the automotive sector and on VDT workstation comfort.

This paper analyzes how workers position themselves at workstations used in industrial processes that sew together the edges of mattresses. The aim of the analysis is to determine whether workers can position themselves in ways that allow them to carry out activities in simple and economical ways.

The Strain Index was used to identify the most critical and risky work phases in order to evaluate workers' risk of biomechanical overload. The OCRA checklist was used to evaluate the overall risk level associated with repeated completions of the total cycle of work and to develop a virtual-postural analysis to evaluate workers' perceived levels of discomfort.

For the virtual-postural analysis, DELMIA ${ }^{\circledR}$ software was used to virtually model a workstation, and records of activities and the postures associated with various repetitive actions were gathered in a non-invasive manner with cameras and video cameras. CaMAN ${ }^{\circledR}$ software developed by the researchers from the Department of Industrial Engineering in Salerno (Italy) was used to calculate comfort indexes.

An analysis of the comfort indexes was used to make as the basis for suggestions to correct workers' postures and for plans to redesign the workstations in order to improve ergonomics and allow workers to perceive them as more comfortable.
\end{abstract}

Keywords: Comfort evaluation criteria, digital human modeling, ergonomics, non-invasive postural analysis, redesign.

\section{INTRODUCTION}

Machine ergonomic studies are able to identify design evaluation parameters that help designers, buyers and users to choose product solutions. In industrial environments, especially in transport systems (like automobiles, trains, and operator-run machines) and in industrial plants (equipped with tooling machines or that have assembly lines), ergonomic factors are taken into account in product and process development because they are a key component of the human-machine interface. During the last decade, a number of researchers and designers have made improvements to the ergonomics and comfort of their products and work-cells (processes). In fact, although new ways of approaching ergonomics in recent years have led to improved comfort and usability of products, we have not seen the evolution of common guidelines that designers can use to optimize this "time-consuming" activity. Nowadays, a typical ergonomic analysis covers an entire working day.

The most used method for ergonomic analysis is based on the following two steps: 1) Direct and indirect

*Address correspondence to this author at the Department of Industrial Engineering, University of Salerno, via Giovanni Paolo II, 132, 84084, Fisciano (SA), Italy; Tel: +39-089-964311; Fax: +39-089-964037;

E-mail: anaddeo@unisa.it (videotaped) observations of users and workplaces; 2) information collection about work-cells and work-cycles.

During the last two decades, the market has been impacted by several laws:

- $\quad$ EN ISO (International Organization for Standardization) 14738, September 2002 "Safety of machinery - anthropometric requirements for the design of workstations at machinery" [1];

- $\quad$ ISO 11226/2000 - "Ergonomics - evaluation of static working posture" [2];

- EN 1005-3/2009 "Safety of machinery - human physical performance - part 3: recommended force limits for machinery operation" [3].

These standards set several geometric parameters that must be met in machine design processes for a number of products (from the guidance systems of trains to supermarket cashier stations). It is notable that these standards lack guidelines for the evaluation of the ergonomic factors that affect human-machine interaction. An operator's use of a machine (as a product or as part of a process) generally consists of a period of time during which the operator repeats actions several times per hour/per day. The stress caused by repetitive actions can depend on a number of design factors, like, for example, the position of command keys and 
function buttons on a machine dashboard. The ergonomic factor is influenced by the kind of interaction that exists between user and machine.

ISO Normative series 11228 deals with ergonomics in the manual handling of objects (extended meaning) and is composed of three parts:

- $\quad$ ISO 11228-1 (Ergonomics - Manual handling - Part 1: Lifting and carrying) [4];

ISO 11228-2 (Ergonomics - Manual handling - Part 2: Pushing and pulling) [5];

- $\quad$ ISO 11228-3 (Ergonomics - Manual handling - Part 3: Handling of low loads at high frequency) [6].

ISO 11228-3 deals with evaluation of risk in cases that require repetitive movements. Risk evaluation is based on two procedures: first, an initial screening of the check list proposed by ISO Standards; second, a detailed evaluation procedure based on International standard methods of Ergonomic analysis like RULA [7], REBA [8], LUBA [9], STRAIN INDEX [10]; OCRA [11], OREGE [12], and others, with a preference given to the OCRA $[13,14]$. Nevertheless, no standard methods are currently available to identify and quantify those parameters that must be evaluated in order to perform a complete comfort analysis.

Over the past 30 years, more than 100,000 scientific papers have been published on the question of comfort and discomfort. The majority have discussed the relationships among environmental factors -such as temperature, humidity, applied forces, and so on- that can affect the perceived level of comfort/discomfort [15]. Several papers assume that a relationship exists between self-reported cases of discomfort and musculoskeletal injuries, with these injuries affecting perceived comfort [16, 17]. However, theories relating comfort to specific products or product design characteristics are rather underdeveloped. The few papers explaining the concept of comfort are by Helander and Zhang [18], De Looze et al. [19], Moes [20] and KuijtEvers et al. [21]. A literature review allows us to identify five key issues concerning the relationship between the subjective perception of comfort/discomfort and factors relating to products, processes, interactions, environment and users:

- $\quad$ Sensory input [22, 23];

- $\quad$ Activities that are focused on measuring comfort [24, 25];

- $\quad$ Different areas of the body [26, 27];

- $\quad$ Effect of the product's physical contours on comfort [14, 28, 29];

- $\quad$ Physical loading [30-33].

Using this foundation, Kuijt-Evers et al. [21] provide an interesting schematization of comfort/discomfort perception mechanisms based on Moes' [20] model, as represented in Fig. (1).

This model has five experiential phases, four of which occur prior to discomfort, the fifth of which is discomfort: interaction (I), effect on the internal body (E), perceived effects (P), appreciation of the effects (A), and discomfort (D). Moes [20] explains that this process is dependent on the person, the seat that is used, the purpose the seat was designed for, and why the seat is used. The author explains that if a person uses a seat designed for a specific purpose, interaction (I) occurs. For example, this interaction may consist of the distribution of pressure throughout the contact area between the person and the seat. Such interaction results in internal body effects (E), such as tissue deformation or the compression of nerves and blood vessels. These effects can be perceived ( $\mathrm{P}$ ) and interpreted as, among other things, pain. The next phase is the appreciation (A) of the effects, either positive or negative. If the appreciation of the effects is negative, this can lead to feelings of discomfort (D).

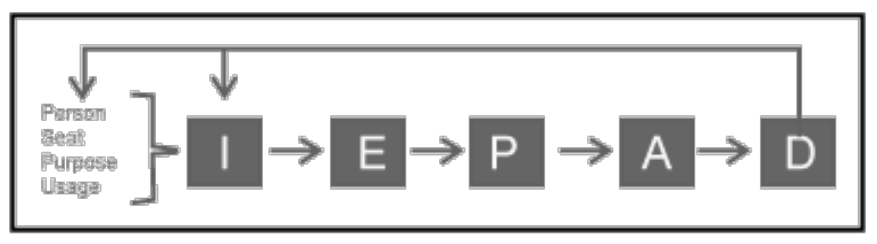

Fig. (1). Moes' model of discomfort perception.

Vink and Hallbeck [23], as follows in Fig. (2), have modified this model:

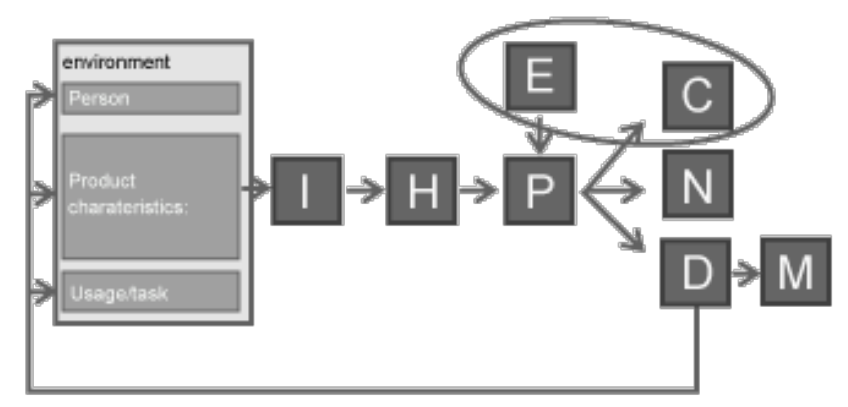

Fig. (2). Vink-Hallbeck model of comfort/discomfort perception.

Interaction (I) is caused by contact (either physical or possibly non-physical contact such as the signal described in the study of De Korte et al. [22]) between the human and the product. This interaction can have several effects on the internal human body $(\mathrm{H})$, such as tactile sensations, body posture changes, and muscle activation. The perceived effects $(\mathrm{P})$ are not only influenced by the actual effects on the human body, but also by expectations (E). Effects are interpreted as comfortable (C), a feeling of nothing $(\mathrm{N})$, or a sense of discomfort (D).

In this model, the body and perceived effects play a fundamental role in comfort/discomfort perception and evaluation. Defining the maximum level of comfort attainable in human postures seems to be one of the most important tasks in this type of comfort evaluation model [13, 34-36], especially if based on the measurement of the angular range of motion (ROM) of each joint.

Certain medical studies have shown that every joint has its own natural rest posture (RP) [37, 38], wherein the muscles are completely relaxed or at a minimum strain level: When this occurs, the geometrical configuration of joints corresponds to the natural position of the resting arms, legs, neck, and so forth. This position appears to minimize musculoskeletal disease and optimize comfort perception [15]. In [36], the problem of identifying and using the RP concept in ergonomic/comfort evaluations is addressed. 
Paper [38] presents an application in which the "neutral zero position" is defined as a parameter for calibrating mechanical instruments in measuring the neck's ROM. Several papers on comfort evaluation like [39] and [40] deal with the postural configuration of astronauts. In both these studies, authors sought to investigate how prolonged exposure to a zero gravity environment affected astronauts' postural configurations in a resting position; results from this literature review cannot, however, be used for our present purposes. Paper [36] shows a new method for objectively evaluating the internal body effects (e.g., body posture and muscle activation) and the perceived effects on several body parts (based on the range of rest posture [RRP]). It was demonstrated that anthropometric parameters could be used to evaluate users' well-being level (comfort).

Papers [41] and [42] present a new software named CaMAN $^{\circledR}$ that was developed by authors and is, based on posture analysis. This software allows making quantitative evaluations of postural comfort.

The aim of this study is to re-design and improve manual assembly workstations through the use of this last mentioned quantitative method.

\section{TEST-CASE AND METHODS}

The work shift analyzed is 8 hours long in duration, from 8 a.m. to 5 p.m. with an hour break for lunch from 1 p.m. to 2 p.m. The work-cycle has been divided into repetitive activities and the duration of each of these activities has been measured, based on an analysis of video recordings of the activities.

The machine being analyzed is a semi-automatic edgebending machine Type H304 made in Germany.

The analysis of the duration of activities' times allows us to calculate an average time of $148 \mathrm{sec}$. for the total repetitive cycle.

The result of $148 \mathrm{sec}$. is reached by averaging the working time for sewing a single mattress and the average working time for sewing a double mattress; the difference between the two cycle durations is approximately $4 \mathrm{sec}$.

The sequence of activities is listed below:

1. The worker presses the button for the feed and for the stop of the rollers;

2. The worker moves the mattress near the sewing machine;

3. The worker presses the button to calibrate the height of the sewing machine;

4. The worker takes the tickets that have to be sewed on the mattress;

5. Automatic sewing of first side: during this operation the worker checks the process and uses arms and hands to guide the mattress;

6. The worker moves the mattress away from the sewing machine;

7. Automatic ribbon cutting;

8. Automatic quick sewing;
9. Automatic thread trimming;

10. The worker leaves the mattress for tilting;

11. The worker overturns the mattress;

12. The worker moves the mattress near the sewing machine;

13. Automatic Sewing on second side;

14. The worker moves the mattress away from the sewing machine;

15. Automatic ribbon cutting;

16. Automatic quick sewing;

17. Automatic thread trimming;

18. The worker moves the mattress away from the sewing machine;

19. The worker presses the button for the feed and for the stop of the rollers.

The analysis of the entire cycle of work shows that the sewing of the mattresses' edges is considered the most critical and repetitive activity.

\subsection{Modeling of Workstation and Worker}

CATIA $^{\circledR}$ V5R16 was used for virtual-modelling of the edge bender. Several elements were modeled individually and then combined.

In Fig. (3), the faithful modeling of the workstation is shown.

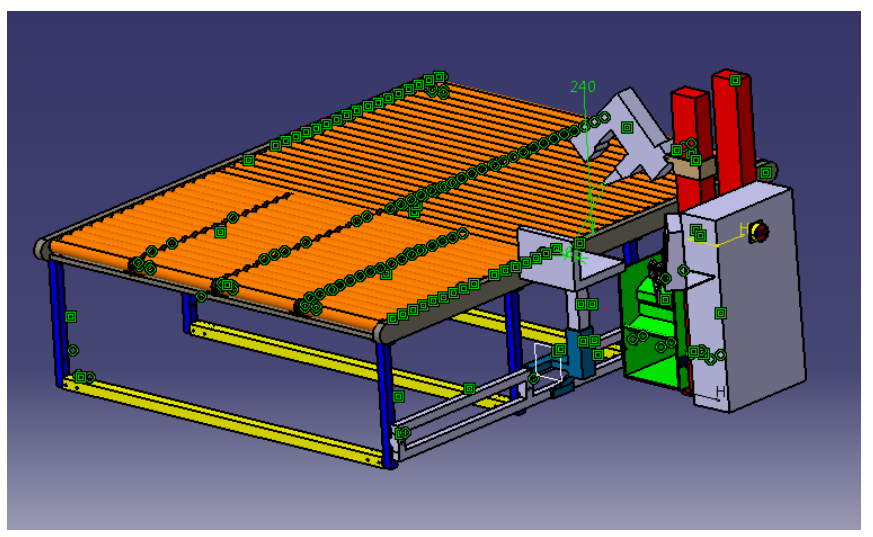

Fig. (3). Virtual workstation.

A "dummy" based on a real worker's anthropometric measures has been used to model the worker. The measures were: height $(1630 \mathrm{~mm})$, joint shoulder-elbow $(303 \mathrm{~mm})$, joint elbow-wrist (241 mm), and shoulder width (390).

Several pictures were taken of each posture to be analyzed. These snapshots were subjected to angular detection using Kinovea ${ }^{\circledR}$ software rel. 0.8.7.

The reference position for detection and measurement of joint angles was the geometric-zero position. This position is defined as the one that allow the maximum state of comfort among the values in the "Comfort Range of Motion" (CROM) [36].

Results of acquisition, elaboration by Kinovea and modeling by CATIA and DELMIA are shown below: 


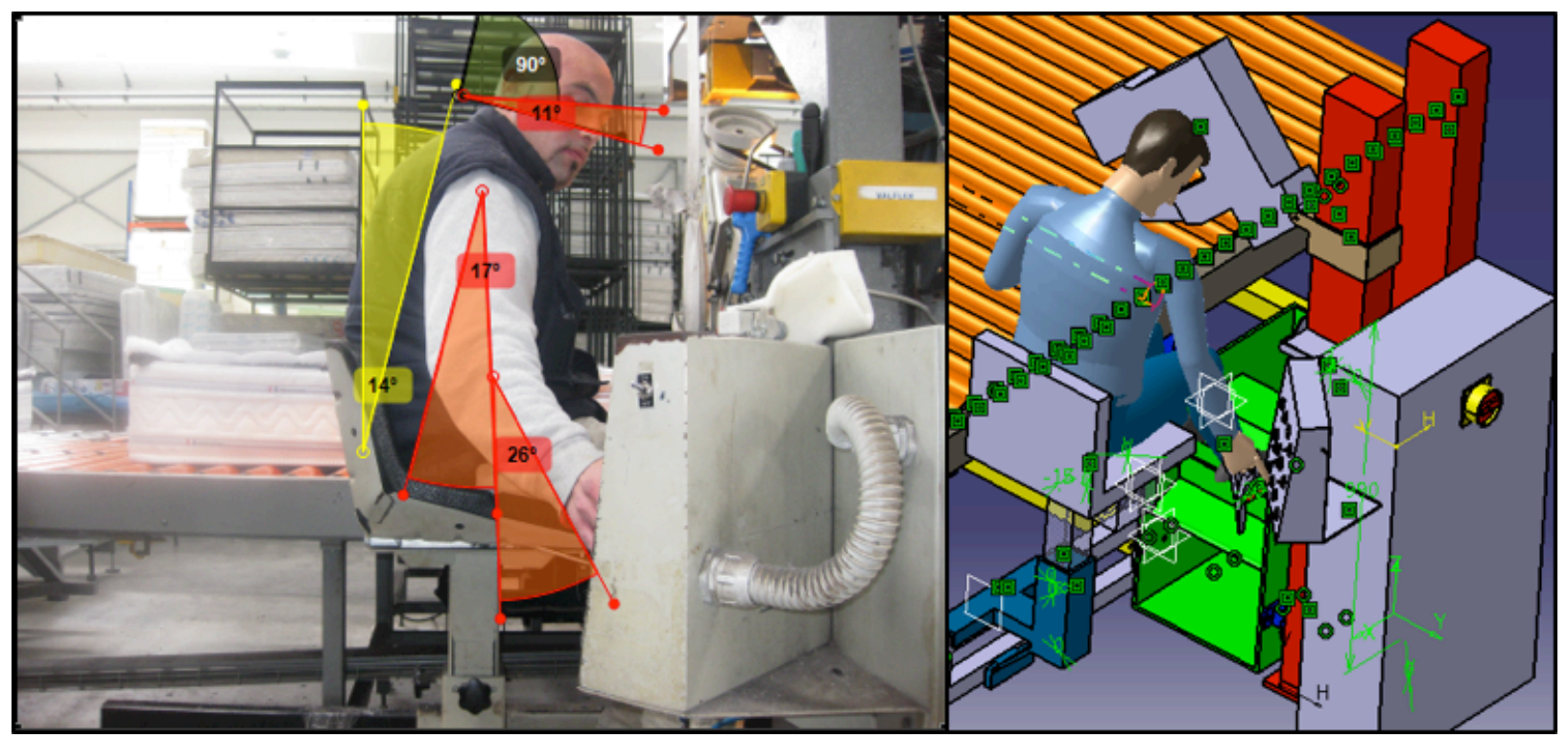

Fig. (4). Angles' detection: pressure button for stapler's height adjustment.

Pushing the button that changes the height of the stapler (Fig. 4): shoulder flexion, shoulder abduction, elbow flexion and neck frontal flexion were detected;

Pushing the mattress feed button (Fig. 5): shoulder flexion, shoulder abduction, elbow flexion and neck frontal flexion were detected;

Sewing (right hand - Fig. 6): shoulder flexion, elbow flexion and neck frontal flexion were detected;

- Sewing (left hand - Fig. 6): shoulder flexion, shoulder abduction, elbow flexion and neck frontal flexion were detected;
Taking the mattress (Fig. 7): shoulder flexion, shoulder abduction, elbow flexion and neck frontal flexion were detected;

Removing the mattress (Fig. 8): shoulder flexion, shoulder abduction, elbow flexion, radio-ulnar deviation of the wrist and neck frontal flexion were detected;

Overturning (right hand - Fig. 9): shoulder flexion, elbow flexion and neck frontal flexion were detected;

Overturning (left hand - Fig. 9): shoulder flexion, shoulder abduction, elbow flexion and neck frontal flexion were detected;

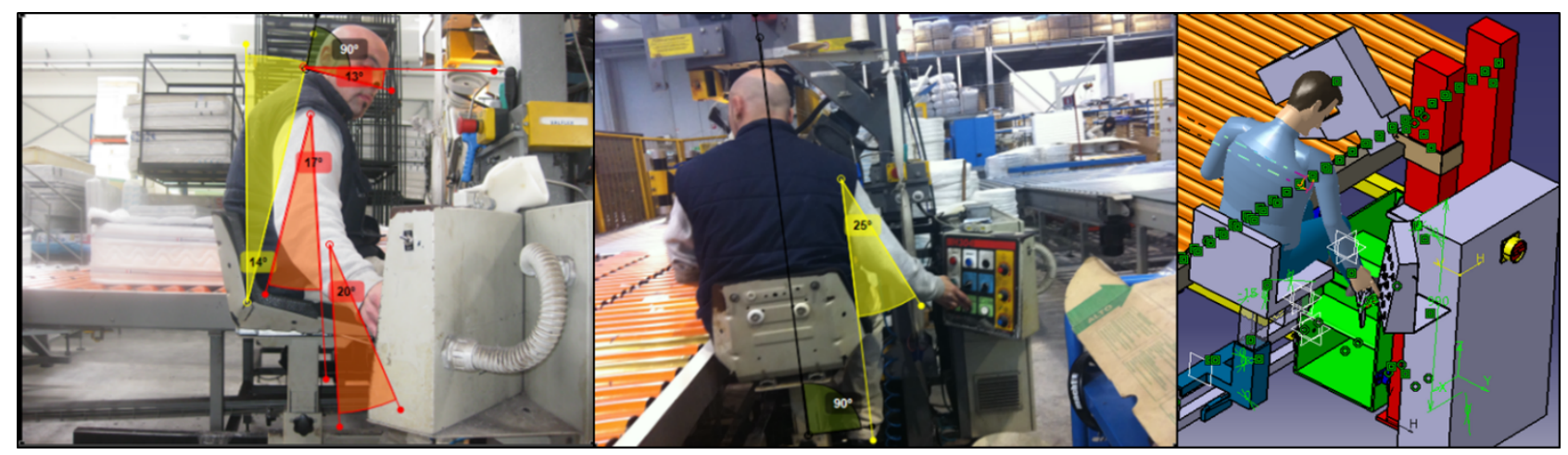

Fig. (5). Angles' detection: pressure button to move forward the mattress.

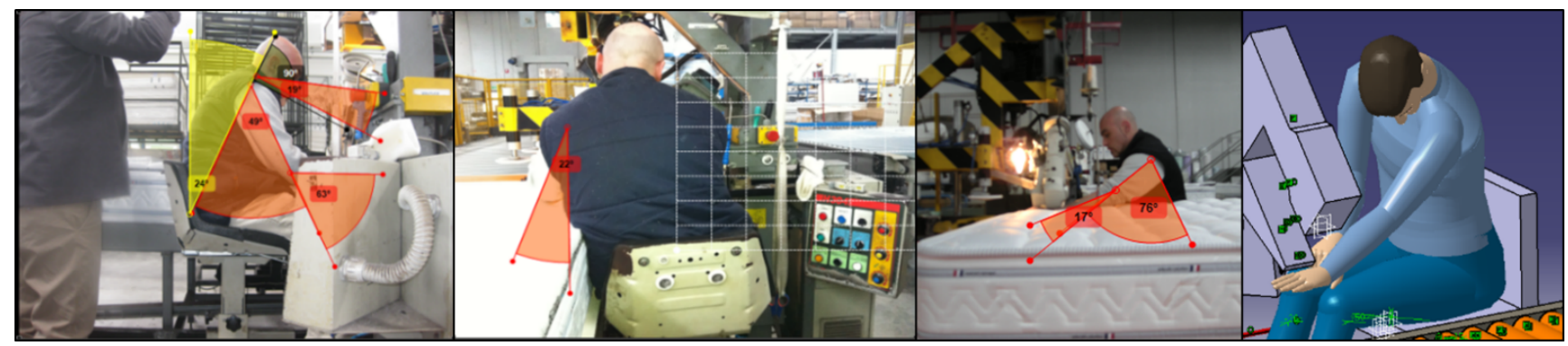

Fig. (6). Angles' detection: sewing. 


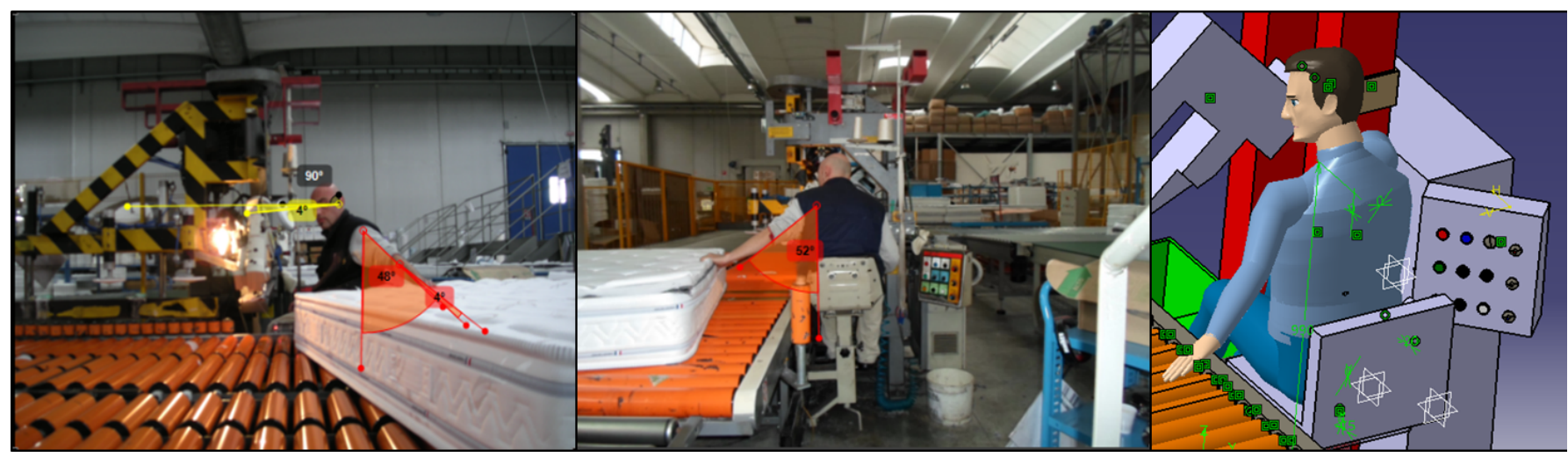

Fig. (7). Angles' detection: taking the mattress.

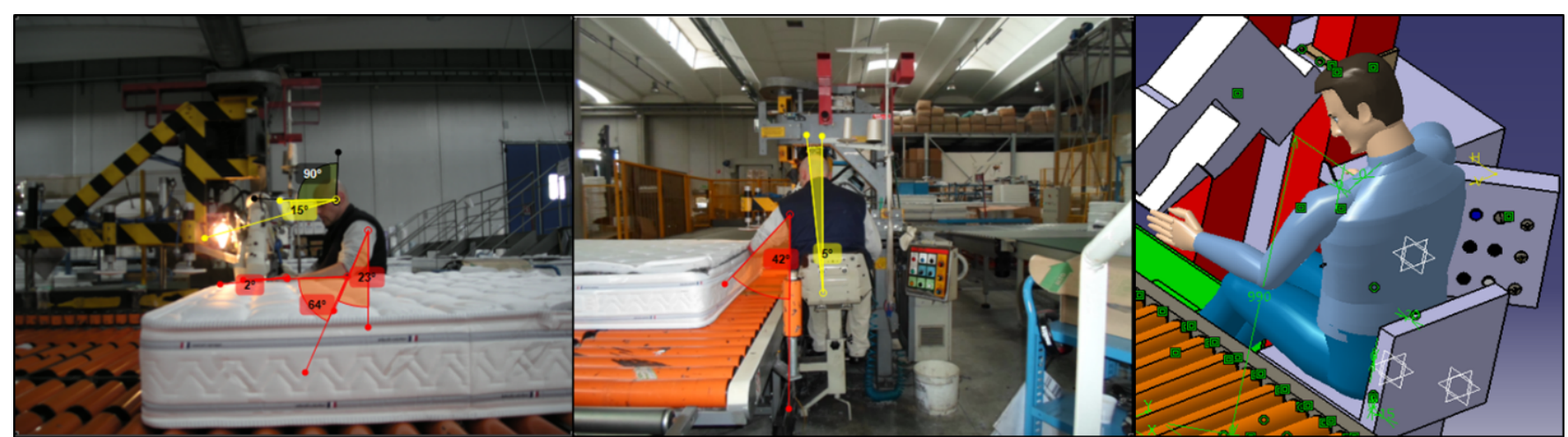

Fig. (8). Angles' detection: removing the mattress.

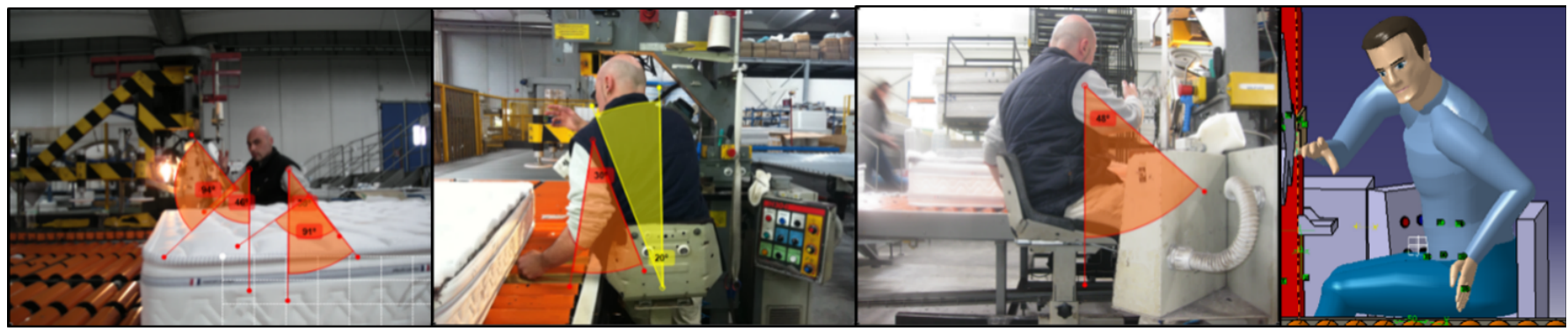

Fig. (9). Angles' detection: overturning the mattress.

Taking the scissors (Fig. 10): shoulder flexion, shoulder abduction, elbow flexion, radio-ulnar deviation of the wrist and neck frontal flexion were detected;
Taking the tickets (Fig. 11): shoulder flexion, shoulder abduction, elbow flexion, radio-ulnar deviation of the wrist and neck frontal flexion were detected;

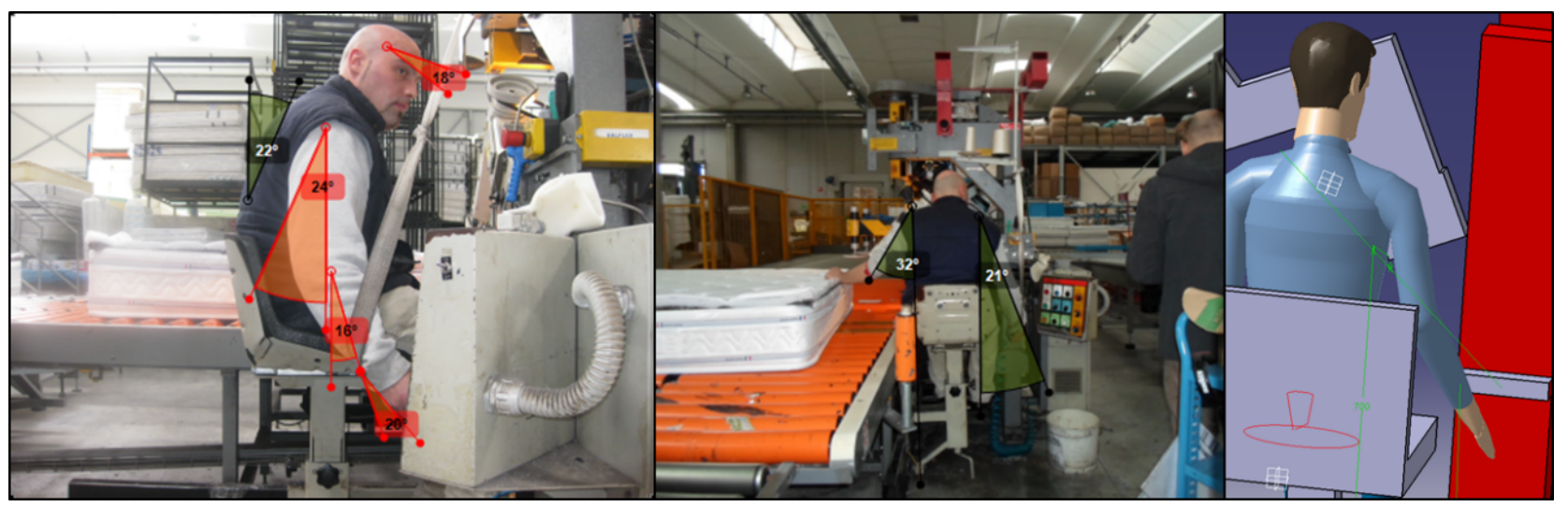

Fig. (10). Angles' detection: taking the scissors. 


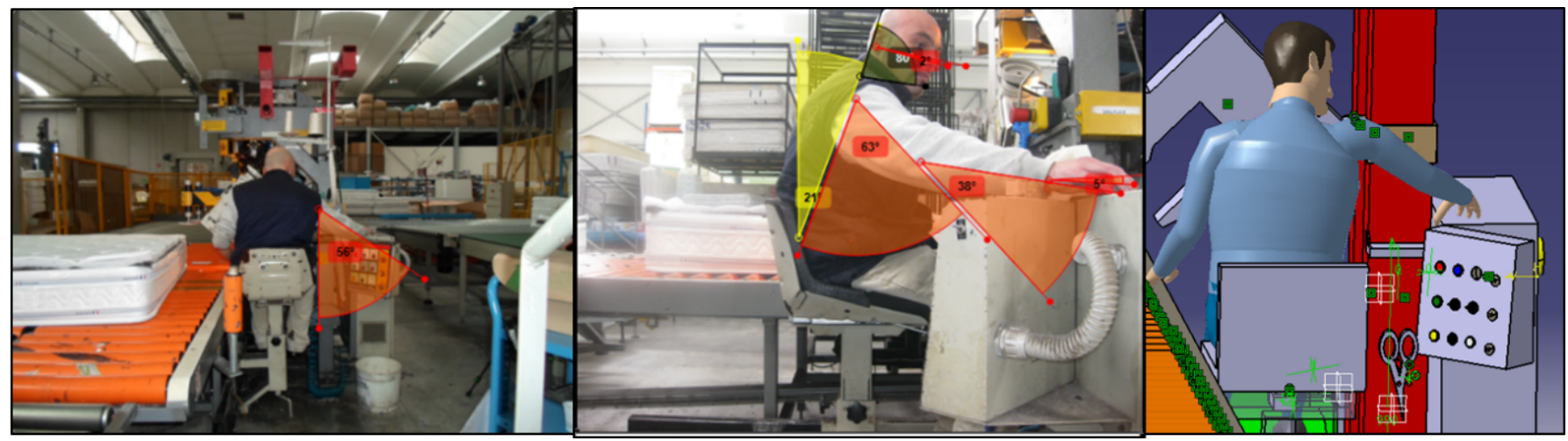

Fig. (11). Angles' detection: taking the tickets.

In the virtual environment, the dummy was placed inside the edge bender assembly in order to carry several checks. The "reach position" function allows the manikin to move itself into the desired position. This acquisition method has been checked and validated by comparing the output angles calculated by the software with those obtained from analysis of the pictures.

Photographic data acquisition may cause some detection errors that were analyzed and controlled in order to ensure that all values were in an acceptable range [44]. Taking pictures from only two points of view when the work was not in progress (a steady-state picture) was very useful as a way to avoid errors. Some of the acquired angles were slightly modified to correct for inadequacies of the photographic acquisition method.

An extra "visibility" analysis was made; this demonstrated that some acquired angles showed errors due to acquisition methods. Some angles, for this reason, were modified in order to remain as faithful as possible to workplace reality.

After angles detection, all worker positions were modeled through the "edit posture" and saved into an Excel ${ }^{\circledR}$ table (with the corrected values of angles are in red) as shown in Table 1.
Finally, the simulation of the movements of the manikin, in the studied activities, has been performed.

\subsection{Methods of Ergonomic Evaluation}

The repetition of work activities is a factor to consider very carefully. Repetition can lead to biomechanical overload of the upper limbs (SBAS) that results in trauma and injuries from stress, and micro-traumas that are repeated over time and have a cumulative effect.

In order to evaluate the possibility of biomechanical overload, risk factors associated with repetitive movements of upper limbs must be considered in connection with the total time duration of repetitive movements.

ISO 11228-3 strongly recommends the use of the OCRA analysis as the risk assessment method. The classic OCRA checklist is the instrument of choice to develop a risk map that defines risk zones for workstations, with green representing no risk, yellow a possible or slight risk, and red showing risk areas. Alternatively, the Strain Index method is based on the principles of biomechanics, physiology and epidemiology, and considers the intensity and duration of effort, as well as the duration of recovery periods. After the

Table 1. Angles.

\begin{tabular}{|c|c|c|c|c|c|c|c|c|c|}
\hline High button & 17 & 25 & 26 & 4 & -9 & 9 & 10 & 3,047 & 34,759 \\
\hline Sewing (right) & 49 & -18 & 63,617 & 75,504 & 1,649 & 1,305 & 0 & 3,047 & 0 \\
\hline Tickets & 54 & 54 & 35 & 86,359 & 10 & 7 & 2 & 0 & 23,759 \\
\hline Overturning (right) & 48 & 3 & 94 & 36 & -1 & 2 & -8 & 0 & $-33,589$ \\
\hline Overturning (left) & -34 & 30 & 87 & 0 & $-29,545$ & 20 & -8 & 0 & $-33,589$ \\
\hline Taking the mattress & -33 & 52 & 4 & 52,128 & $-29,545$ & 0 & 6 & 0 & -45 \\
\hline
\end{tabular}


ergonomic analysis was performed, a comfort evaluation using CaMAN software was completed.

\subsubsection{Strain Index}

The Strain Index [10] is a method used to analyze work tasks in order to determine the risk of disorders or musculoskeletal diseases of the upper limbs. Strain Index calculations (Table 2) are based on the determination of six variables:

1. The intensity of the effort needed to perform the task;

2. The duration of the effort;

3. The number of efforts per minute;

4. The posture assumed by the hand-wrist segment performing the task;

5. The speed of execution of the task;

6. The total time spent performing the task during the workday.

The Strain Index was used to assess the most repetitive and biomechanically risky tasks, specifically:

- $\quad$ The worker presses the button to feed and stop the rollers;

- $\quad$ The worker presses the button to vary the height of the sewing machine;

- $\quad$ The sewing task;

- The worker draws the mattress near the sewing machine;

- $\quad$ The worker moves the mattress away from the sewing machine;

- $\quad$ The worker takes the scissors;

- $\quad$ The worker overturns the mattress;

- $\quad$ The worker takes the tickets that have to be sewed on the mattress.

The risk level of the sewing activity is unacceptably high:

Sewing the right side is dangerous because the right arm is hanging near the edge of the mattress while the task is performed.

- Only a probability of risk is associated when sewing the left side; the left arm leans on the mattress and pushes, with small movements, the mattress under the needle of the sewing machine.

- $\quad$ For the others tasks the risk level is acceptable.

The reason for this result is connected to the overall amount of time used to perform each of the various tasks. More time is devoted to sewing activity than to any of the other ones.

\subsubsection{OCRA Checklist}

The classic OCRA checklist [43] is the tool to use for a first mapping of the risk. It allows risk levels to be assessed for each task and assigned to one of three risk level bands: green band (no risk), yellow band (possible or slight risk) and a red risk band.

The checklist can generally be completed by observing the worker in real time. In this study, the analysis for the checklist was also based on videos that were recorded during the work activity. The values calculated by the OCRA checklist can be read in the following Table 3 and are compared with the OCRA ones.

The final values of the OCRA analysis (Table 4) show two situations: a slight risk zone for the right upper limbs and an acceptable risk zone for the left upper limbs. This result agrees with the result of the STRAIN INDEX analysis.

The risk to the right upper limbs is greater than the risk to the left limbs because the worker uses the right limbs more than the left limbs to complete activities, and the left upper limbs are held more closely to the mattress. Additionally, the left upper limbs make more "free-hand" movements: when the worker draws the mattress near the sewing machine, when the worker moves the mattress away from the sewing machine and when the worker overturns the mattress.

The analytical methods used suggest that multiple factors are associated with the problem, of which the definition is uncertain, and for which a solution requires a synthesis of factors.

Multiple assessment methods must be applied and risk

Table 2. Results of strain index.

\begin{tabular}{|c|c|c|}
\hline & & Strain Index tot \\
\hline \hline Pressing stop/move forward button of rollers & Right & 0.0625 \\
\hline Pressing button for stapler's height adjustment & Right & 13.5 \\
\hline Sewing & Right & 5.0625 \\
\cline { 2 - 3 } & Left & 0.8437 \\
\hline Taking the mattress & Left & 0.5630 \\
\hline Removing the mattress & Left & 0.5625 \\
\hline Scissors & Right & 1.6875 \\
\hline \multirow{2}{*}{ Overturning the mattress } & Right & 0.5625 \\
\hline Tickets & Left & 0.5625 \\
\hline
\end{tabular}


Table 3. Score analysis OCRA.

\begin{tabular}{|c|c|c|c|}
\hline CHECKLIST OCRA & OCRA INDEX & BAND & RISK \\
\hline \hline until 7,5 & until a 2,2 & GREEN & ACCEPTABLE RISK \\
\hline $7,6-11,0$ & $2,3-3,5$ & YELLOW & BORDERLINE O LIGHT RISK \\
\hline $11,1-14,6$ & $3,6-4,5$ & LIGHT RED & MEDIUM RISK \\
\hline $14,1-22,5$ & $4,6-9,0$ & RED & HIGH RISK \\
\hline$>22,6$ & $>9,1$ & VIOLET & HIGH RISK \\
\hline
\end{tabular}

Table 4. Results of checklist OCRA.

Final Score Weighted Net Life

RIGHT

LEFT
8,98

5,99 factors must be analyzed on the basis of information from the different indexes used in order to avoid serious errors of interpretation.

It was essential, therefore, to undertake a postural analysis of all the activities, but with a particular attention paid to those activities that were proven critical by the previous analysis.

\subsubsection{Postural Analysis}

The postural analysis consists of several phases:

- $\quad$ The measurement of the joint angles for each posture [44];

- $\quad$ The attribution of a comfort score for each joint;

- The selection of criteria for the combination of the comfort scores.

Each posture can be defined by several anthropometric parameters. These parameters represent the angles of each joint. Once the parameters are determined, it is necessary to associate to each parameter with a comfort score. The comfort scores, which are obtained using $\mathrm{CaMAN}^{\circledR}$, have to be combined according to criteria that allow to evaluate the posture comfort index. In order to have a more meaningful result, the comfort scores have to be compared on the basis of their sum and their mean. The sum and the mean are two simple and significant criteria, both of which allow a first valuation of the comfort index. The results of the analysis of this comfort indexes are shown in Table 5. CaMAN ${ }^{\circledR}$ software assigns a comfort score to angular intervals of the various joints in which are divided the CROM. The comfort is scored on a scale of one to ten, where one is the minimum comfort and ten is the maximum comfort. The assessment model is tailored to an analysis of the upper body limbs. The joints involved are, therefore:

- Neck: flexion/extension, lateral flexion, rotation;

- Shoulder: flexion/extension, abduction/adduction;

- $\quad$ Elbow: flexion/extension, pronation/supination;

- Wrist: flexion/extension, radio/ulnar deviation.

\section{DISCUSSION}

Although ergonomic analysis makes it possible to define the level of risk associated with repetitive activities, it is essential to associate this analysis with a comfort analysis. This step is important to determine the relationship of comfort to irregular postures. The two analyses must be conducted successively and the results checked at each stage.

The aim is to improve comfort indexes by relieving the need of the worker to perform certain movements and then to check if such relief had a positive effect on the ergonomic analysis.

From the analysis of comfort indexes (Table 5), it is possible to conclude:

Red values were modified when it was discovered that some of the bad worker postures that yielded angles with red values were, in fact, a result of the workstation being turned off during the photo capture;

- Green values cannot be increased because the posture in the sewing activity cannot be altered: the left forearm must rest on the mattress; 
Table 5. Comfort indexes.

\begin{tabular}{|c|c|c|c|c|c|c|c|c|c|c|}
\hline & \multicolumn{2}{|c|}{ Comfort Index Neck } & \multicolumn{2}{|c|}{ Comfort Index Elbow } & \multicolumn{2}{|c|}{ Comfort Index Shoulder } & \multicolumn{2}{|c|}{ Comfort Index Wrist } & AVG & $\begin{array}{c}\text { AVG } \\
\text { Changed }\end{array}$ \\
\hline Down Button & 5,8 & 9,9 & 10 & 9,5 & 9,6 & 5,8 & 10 & 6,3 & 8,0 & 8,3 \\
\hline High Button & 2,3 & 9,9 & 9,7 & $\mathbf{9 , 5}$ & 9,6 & 5,8 & 10 & 6,3 & 7,4 & 7,9 \\
\hline Sewing (right) & 9,9 & 9,9 & 6,7 & 1,5 & 6,9 & 10 & 10 & 9,9 & 6,2 & 8,1 \\
\hline Tickets & 6,4 & 9,9 & 7,3 & 1 & 6,8 & 5,2 & 9,9 & 8,1 & 5,6 & 6,8 \\
\hline Overturning (right) & 5,8 & 9,9 & 5,4 & 6,4 & 6,9 & 10 & 10 & 9,8 & 7,3 & 8,0 \\
\hline Overturning (left) & 5,8 & 9,9 & 5,6 & 9,7 & 1,1 & 5,3 & 5,8 & 4,3 & 5,9 & \\
\hline Taking the Mattress & 1 & 9,9 & 10 & 5,9 & 1,1 & 5,1 & 5,8 & 10 & 5,4 & 6,1 \\
\hline
\end{tabular}

- Although yellow squares indicate a low comfort index, it is not possible to make any modifications because of the "edge bender" configuration: the seat is supported on the top of worktable. This configuration only allows for rotating the torso, not the legs, and these results in lower indexes.

The activities with risk were: grasping the ticket, grasping the mattress and overturning the mattress. Drawing the mattress near to the sewing machine is the one activity that allows the worker some flexibility to choose a less incongruous posture. The objective was, therefore, to improve the comfort indexes starting with the CROM intervals and the optimal values of comfort associated with intervals. The way to do is force the use of angles with the highest comfort indexes, then to modify these angles (Table 6) in order to obtain natural postures that can form the basis of a possible redesign.

\subsection{Comfort Driven Re-Design}

In order to resolve the problems with the activities revealed by the analysis results presented above, it was necessary to make changes to the edge bender layout. Proposed changes consisted of a system that allowed the seat to move sideways and a slab to lay tickets that was longer than the existing slab.

\subsubsection{Rotating Seat}

Fig. (12) shows the redesigned seat. The new seat differs from the original because it can move laterally and rotate to the right. This new configuration gives the worker more working space and requires less torso rotations. When the worker has to overturn the mattress, for example, he does not need to rotate his torso because he can rotate the seat. Lateral movement of the upper part of the seat is constrained by a guide. When the seat arrives at the end of the guide, it can rotate within a cylindrical pocket (Fig. 13). Seat movement is activated by a button under the seat, through the action of a cylindrical piston.

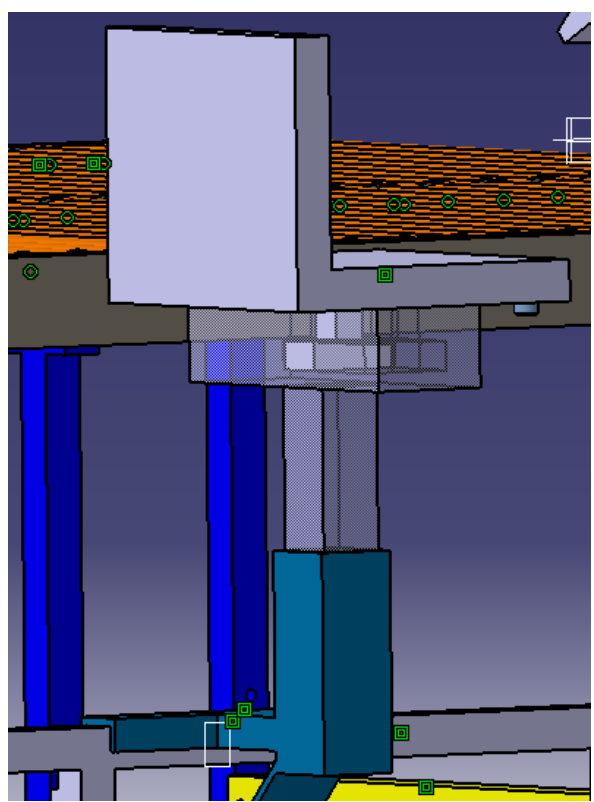

Fig. (12). Rotating chair.

Table 6. Angles of design proposal.

\begin{tabular}{|c|c|c|c|c|c|c|c|c|c|}
\hline & \multicolumn{2}{|c|}{ Arm } & \multicolumn{2}{c|}{ Forearm } & \multicolumn{2}{c|}{ Hand } & \multicolumn{2}{c|}{ Head } \\
\cline { 2 - 10 } & Flexion & Abduction & Flexion & Pronation & Flexion & Radial Deviation & Flexion & Lateral & Rotation \\
\hline \hline Tickets & 66,3 & 10,6 & 7,4 & 87,0 & $-6,9$ & 0 & 0 & 0 & $-4,2$ \\
\hline Overturning (right) & 67,6 & 0 & 5,4 & 0 & -1 & 2 & -2 & 0 & -8 \\
\hline Overturning (left) & -11 & 14 & 73 & 0 & $-16,5$ & 15 & -2 & 0 \\
\hline
\end{tabular}




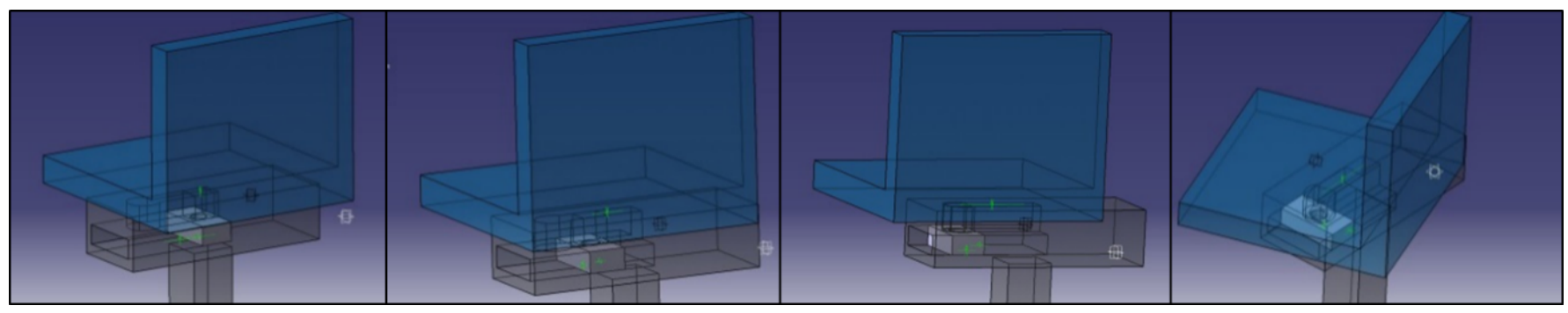

Fig. (13). The rotation of the seat.

Figs. $(\mathbf{1 4}, \mathbf{1 5})$ show the lower and upper parts of the seat. The upper part is composed of a horizontal plane, a seat, and a squared prism for support. This prism is coupled with another prism that forms a rectangular base, through a cylindrical "hinge" that allows the seat to rotate.

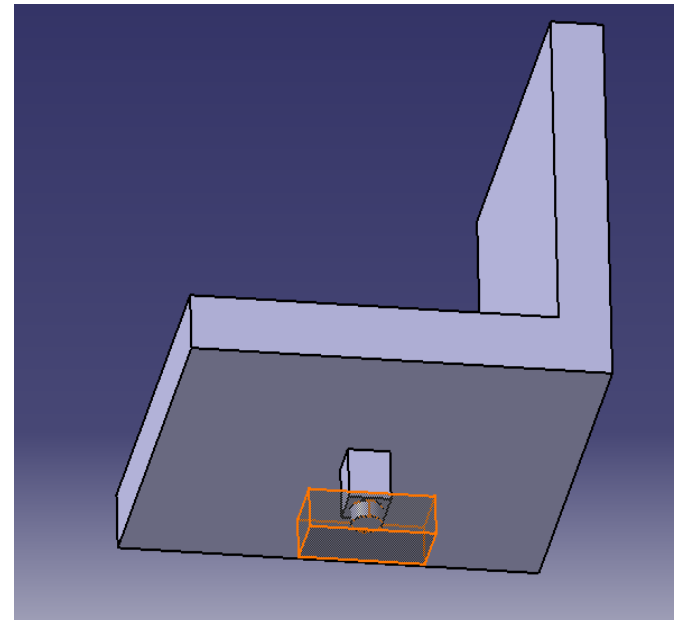

Fig. (14). Top part of the chair.

The lower part consists of a support leg and of a guide along which the seat runs horizontally and can rotate when it reaches the end of the guide.

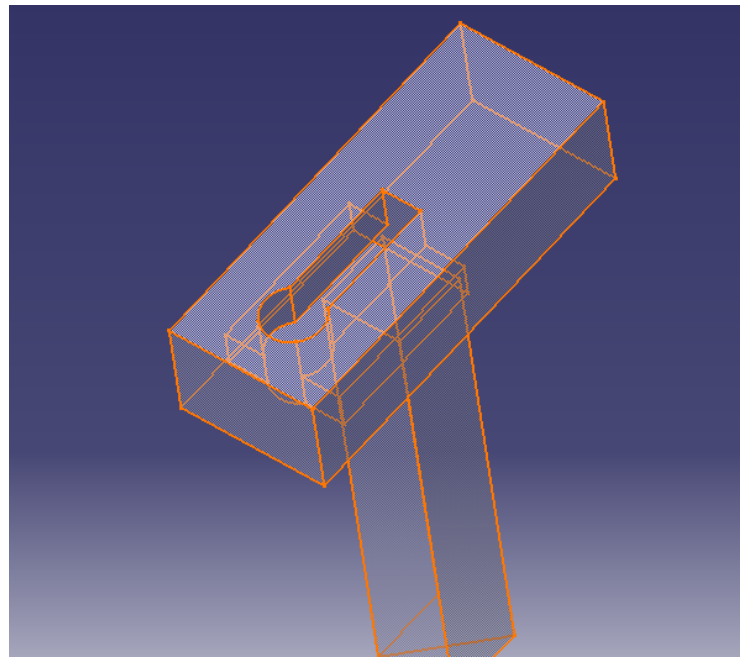

Fig. (15). Down part of the chair.

Horizontal translation is controlled by a pneumatic piston with a bi-stable simple effect actuator. In this way worker movements are guided by the system and do not require worker intervention.

\subsubsection{Support for Sewing Tickets}

The system for placing tickets and the structure of the support on which tickets had to be set were both changed. In the old machine layout, tickets were placed on a control unit shaped like a prism with a rectangular base. In the new machine layout, this control unit has been placed behind the command dashboard and near to the structure that holds the sewing machine.

The old configuration required the worker to lean out to grasp the tickets. Comfort analysis suggested placing the tickets closer to the worker, paying attention to easy accessibility, unimpeded by other elements.

In Fig. (16) it is possible to see the old ticket support. It is immediately apparent that the support is too short to allow holding tickets. Comfort analysis suggested a simple solution: increase the length of the support from $60 \mathrm{~mm}$ to $95 \mathrm{~mm}$, in order to allow holding a 90x90mm ticket.

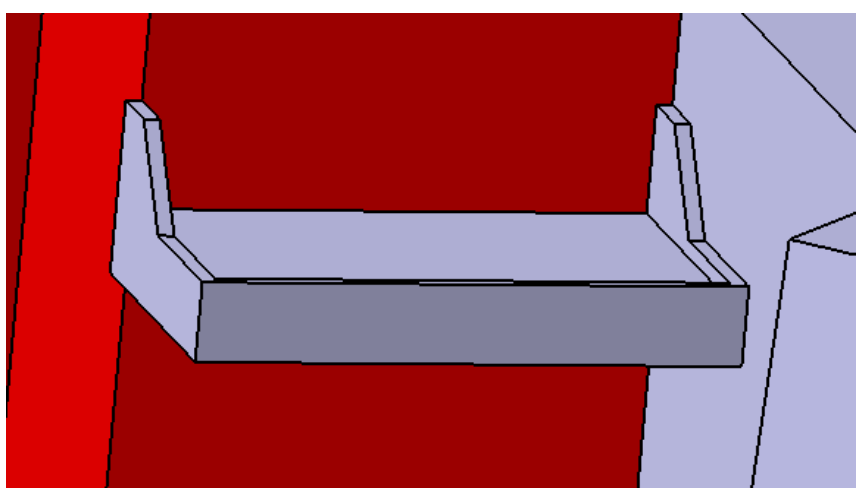

Fig. (16). Tickets support.

\subsection{Final Improvements Results}

After the redesign of machine configuration and parts, we ran a new simulation of all the processes and applied both the Strain Index and OCRA checklist in order to determine if there were improvements due to the redesign. In new simulation, the following new activities were introduced:

- $\quad$ Put pressure on the button to move seat laterally;

- $\quad$ Continue pressure on the button while the seat moves;

- Put pressure on the button to return the seat to a position near the edge bender.

Tables 7-9 present the new angles assumed by the dummy. 
Table 7. Angles assumed by the dummy with the activities changed (arm, clavicle, forearm).

\begin{tabular}{|c|c|c|c|c|c|c|c|}
\hline & \multicolumn{3}{|c|}{ ARM } & \multicolumn{2}{|c|}{ CLAVICOLA } & \multicolumn{2}{|c|}{ FOREARM } \\
\hline & FLEXION & ABDUCTION & ROTATION & FLEXION & ELEVATION & FLEXION & PRONATION \\
\hline $\begin{array}{l}\text { TICKETS WHITOUT } \\
\text { ROTATING SEAT }\end{array}$ & 66,317 & 10,654 & 44,297 & 13,664 & 17,698 & 7,375 & 87,059 \\
\hline $\begin{array}{l}\text { TICKETS WHITIN } \\
\text { ROTATING SEAT }\end{array}$ & 45,836 & 3,532 & 50,71 & 20 & 15,416 & 3,642 & 90,653 \\
\hline $\begin{array}{l}\text { OVERTURNING WITHIN } \\
\text { ROTATING SEAT } \\
\text { (RIGHT HAND) }\end{array}$ & 67,679 & $\mathbf{0}$ & 50,71 & 20 & 53 & 5,401 & $\mathbf{0}$ \\
\hline $\begin{array}{l}\text { OVERTURNING WITHIN } \\
\text { ROTATING SEAT } \\
\text { (LEFT HAND) }\end{array}$ & -11 & 14 & 20 & 20 & 9,135 & 73 & $\mathbf{0}$ \\
\hline
\end{tabular}

Table 8. Angles assumed by the dummy with the activities changed (full spine, lumbar, thoracic).

\begin{tabular}{|c|c|c|c|c|c|c|c|c|c|}
\hline & \multicolumn{3}{|c|}{ FULL SPINE } & \multicolumn{3}{|c|}{ LUMBAR } & \multicolumn{3}{|c|}{ THORACIC } \\
\hline & FLEXION & LATERAL & ROTATION & FLEXION & LATERAL & ROTATION & FLEXION & LATERAL & ROTATION \\
\hline $\begin{array}{l}\text { TICKETS } \\
\text { WHITOUT } \\
\text { ROTATING } \\
\text { SEAT }\end{array}$ & 20 & -5 & 18 & 13,132 & $-1,548$ & 2,277 & 5,216 & $-4,087$ & $-15,831$ \\
\hline $\begin{array}{l}\text { TICKETS } \\
\text { WHITIN } \\
\text { ROTATING } \\
\text { SEAT }\end{array}$ & $\mathbf{0}$ & -5 & 18 & $\mathbf{0}$ & $-1,548$ & 2,277 & $\mathbf{0}$ & $-4,087$ & 16,174 \\
\hline $\begin{array}{l}\text { OVERTURNIN } \\
\text { G WITHIN } \\
\text { ROTATING } \\
\text { SEAT } \\
\text { (RIGHT HAND) }\end{array}$ & 17 & 10 & -60 & 11,158 & 3,097 & $-7,591$ & 4,432 & 8,176 & $-53,572$ \\
\hline $\begin{array}{l}\text { OVERTURNIN } \\
\text { G WITHIN } \\
\text { ROTATING } \\
\text { SEAT } \\
\text { (LEFT HAND) }\end{array}$ & 17 & 10 & -60 & 11,158 & 3,097 & $-7,591$ & 4,432 & 8,176 & $-53,572$ \\
\hline
\end{tabular}

Table 9. Angles assumed by the dummy with the activities changed (hand, head).

\begin{tabular}{|c|c|c|c|c|c|}
\hline & \multicolumn{2}{|r|}{ HAND } & \multicolumn{3}{|c|}{ HEAD } \\
\hline & FLECTION & RADIAL DEVIATION & FLEXION & LATERAL & ROTATION \\
\hline TICKETS WHITOUT ROTATING SEAT & $-6,961$ & 0 & 0 & 0 & $-4,207$ \\
\hline TICKETS WHITIN ROTATING SEAT & 3,673 & 0 & 11 & 0 & $-4,241$ \\
\hline $\begin{array}{l}\text { OVERTURNING WITHIN ROTATING } \\
\text { SEAT } \\
\text { (RIGHT HAND) }\end{array}$ & -1 & 2 & -2 & 0 & -8 \\
\hline $\begin{array}{l}\text { OVERTURNING WITHIN ROTATING } \\
\text { SEAT } \\
\text { (LEFT HAND) }\end{array}$ & $-16,545$ & 15 & -2 & 0 & -8 \\
\hline
\end{tabular}


Table 10. Strain index tickets.

\begin{tabular}{|c|c|c|c|c|}
\hline \multicolumn{4}{|l|}{ TICKETS } & \\
\hline \multirow{4}{*}{ STRAIN INDEX } & \multicolumn{3}{|l|}{ SI $<3$ SAFE } & \\
\hline & \multicolumn{3}{|l|}{$3<$ SI $<5$ UNCERTAIN } & \\
\hline & \multicolumn{3}{|l|}{ 5<SI $<7$ SOME RISK } & \\
\hline & \multicolumn{3}{|l|}{ SI>7 HAZARDOUS } & \\
\hline & & & OLD RATE & NEW RATE \\
\hline RISK FACTORS & RATING CRITERION & RATING & RIGHT & RIGHT \\
\hline \multirow{5}{*}{ intensity of exertion } & light & 1 & & \\
\hline & somewhat hard & 3 & & \\
\hline & hard & 6 & & \\
\hline & very hard & 9 & & \\
\hline & near maximal & 13 & & \\
\hline \multirow{5}{*}{ duration of exertion ( $\%$ di cycle) } & $<10 \%$ & 0,5 & & \\
\hline & $10-29 \%$ & 1 & & \\
\hline & $30-49 \%$ & 1,5 & & \\
\hline & $49-79 \%$ & 2 & & \\
\hline & $>80 \%$ & 3 & & \\
\hline \multirow{5}{*}{ efforts per minute } & $<4$ & 0,5 & & \\
\hline & {$[4-8]$} & 1 & & \\
\hline & {$[9-14]$} & 1,5 & & \\
\hline & {$[15-19]$} & 2 & & \\
\hline & $>20$ & 3 & & \\
\hline \multirow{5}{*}{ hand/wrist posture } & very good & 1 & & \\
\hline & good & 1 & & \\
\hline & fair & 1,5 & & \\
\hline & bad & 2 & & \\
\hline & very bad & 3 & & \\
\hline \multirow{5}{*}{ speed of work } & very slow & 1 & & \\
\hline & slow & 1 & & \\
\hline & fair & 1 & & \\
\hline & fast & 1,5 & & \\
\hline & very fast & 2 & & \\
\hline \multirow{5}{*}{ duration of task per day (hours) } & $<1$ & 0,25 & & \\
\hline & {$[1-2]$} & 0,5 & & \\
\hline & {$[2-4]$} & 0,75 & & \\
\hline & {$[4-8]$} & 1 & & \\
\hline & $>8$ & 1,5 & & \\
\hline STRAIN INDEX & & & 0,0625 & 0,0937 \\
\hline
\end{tabular}


Table 11. Strain index overturning.

\begin{tabular}{|c|c|c|c|c|c|c|}
\hline \multicolumn{4}{|l|}{ OVERTURNING } & & & \\
\hline \multirow{4}{*}{ STRAIN INDEX } & \multicolumn{3}{|l|}{$\mathrm{SI}<3 \mathrm{SAFE}$} & & & \\
\hline & \multicolumn{3}{|l|}{$3<$ SI $<5$ UNCERTAIN } & & & \\
\hline & \multicolumn{3}{|l|}{$5<$ SI $<7$ SOME RISK } & & & \\
\hline & \multicolumn{3}{|l|}{ SI $>7$ HAZARDOUS } & & & \\
\hline & & & \multicolumn{2}{|c|}{ OLD RATE } & \multicolumn{2}{|c|}{ NEW RATE } \\
\hline RISK FACTORS & RATING CRITERION & RATING & LEFT & RIGHT & LEFT & RIGHT \\
\hline \multirow{5}{*}{ intensity of exertion } & light & 1 & & & & \\
\hline & somewhat hard & 3 & & & & \\
\hline & hard & 6 & & & & \\
\hline & very hard & 9 & & & & \\
\hline & near maximal & 13 & & & & \\
\hline \multirow{5}{*}{ duration of exertion ( $\%$ di cycle) } & $<10 \%$ & 0,5 & & & & \\
\hline & $10-29 \%$ & 1 & & & & \\
\hline & $30-49 \%$ & 1,5 & & & & \\
\hline & $49-79 \%$ & 2 & & & & \\
\hline & $>80 \%$ & 3 & & & & \\
\hline \multirow{5}{*}{ efforts per minute } & $<4$ & 0,5 & & & & \\
\hline & {$[4-8]$} & 1 & & & & \\
\hline & {$[9-14]$} & 1,5 & & & & \\
\hline & {$[15-19]$} & 2 & & & & \\
\hline & $>20$ & 3 & & & & \\
\hline \multirow{5}{*}{ hand/wrist posture } & very good & 1 & & & & \\
\hline & good & 1 & & & & \\
\hline & fair & 1,5 & & & & \\
\hline & bad & 2 & & & & \\
\hline & very bad & 3 & & & & \\
\hline \multirow{5}{*}{ speed of work } & very slow & 1 & & & & \\
\hline & slow & 1 & & & & \\
\hline & fair & 1 & & & & \\
\hline & fast & 1,5 & & & & \\
\hline & very fast & 2 & & & & \\
\hline \multirow{5}{*}{ duration of task per day (hours) } & $<1$ & 0,25 & & & & \\
\hline & {$[1-2]$} & 0,5 & & & & \\
\hline & {$[2-4]$} & 0,75 & & & & \\
\hline & {$[4-8]$} & 1 & & & & \\
\hline & $>8$ & 1,5 & & & & \\
\hline STRAIN INDEX & & & 0,5625 & 1,6875 & 0,5625 & 0,5625 \\
\hline
\end{tabular}


Table 12. Checklist OCRA after redesign.

\begin{tabular}{|l|c|c|}
\hline \multicolumn{2}{|l|}{ CHECKLIST OCRA } \\
\hline & OLD RATE & NEW RATE \\
\hline RIGHT & 8,98 & 9,61 \\
\hline LEFT & 5,99 & 6,62 \\
\hline
\end{tabular}

For all activities, ergonomics and comfort analyses has been completed again; the Strain Index, the OCRA checklist and comfort indexes were re-calculated.

The result is positive for all three tests:

Table 10 shows that the Strain Index for the ticket activity increase in value slightly because the "hand/wrist postures" factor changes from "good" to "very good" and the speed of work that goes from slow to fast. The value for the activity of overturning the mattress also changes in the Strain Index, both for the right and the left limb, as can be seen from the Table 11. The index value for the right limb remained unchanged, while value for the left limb decreased because the effort intensity went from "very hard" to "hard", and hand/wrist posture went from "bad" to "good".
- The OCRA checklist result shows a very slight increase to a score of 0.63 (Table 12) for the right limbs, due mainly to an increase in cycle time (from $148 \mathrm{sec}$ to $152 \mathrm{sec}$ ).

Tables 13 and 14 show how the comfort indexes improved in the direction of excellence because the new configuration gives workers free space for leg movement and allows them to avoid back-spine flexion and torsion. Furthermore, the operator did not need to bend, but can remain with his spine upright when he approaches the tickets support.

\section{CONCLUSION}

The focus of the ergonomic-postural analysis was a workstation used in a plant manufacturing mattresses. The goal of the analysis was to redesign the workstation in a way that would allow workers to perform their activities with less incongruous and incorrect postures. The proposed redesign that resulted from the analysis of ergonomics parameters and the evaluation of the perceived postural comfort was aimed at improving workers' health and safety.

Only two activities involving heavy and complex actions were finally targeted for redesign: the tickets taking action and the mattress overturning action. A workspace redesign was also been made.

Table 13. Values of comfort index before redesign.

\begin{tabular}{|c|c|c|c|c|c|c|c|c|c|c|}
\hline \multirow{5}{*}{ 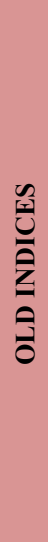 } & & \multicolumn{2}{|c|}{$\begin{array}{l}\text { Comfort Index } \\
\text { Neck }\end{array}$} & \multicolumn{2}{|c|}{ Comfort Index Elbow } & \multicolumn{2}{|c|}{ comfort index shoulder } & \multicolumn{2}{|c|}{ comfort index wrist } & \multirow[b]{2}{*}{ AVG } \\
\hline & ACTIVITIES & Flexion & $\begin{array}{l}\text { Lateral } \\
\text { Flexion }\end{array}$ & $\begin{array}{l}\text { Flexion/ } \\
\text { Extension }\end{array}$ & $\begin{array}{l}\text { Pronation- } \\
\text { Supination }\end{array}$ & $\begin{array}{l}\text { Frontal } \\
\text { Flexion }\end{array}$ & $\begin{array}{l}\text { Adduction/ } \\
\text { Abduction }\end{array}$ & $\begin{array}{l}\text { flexion/ } \\
\text { Extension }\end{array}$ & $\begin{array}{c}\text { Radio } \\
\text { Ulnar } \\
\text { Deviation }\end{array}$ & \\
\hline & Tickets & 6,4 & 9,9 & 7,3 & 1 & 6,8 & 5,2 & 9,9 & 8,1 & 5,6 \\
\hline & $\begin{array}{l}\text { Overturning } \\
\text { (right) }\end{array}$ & 5,8 & 9,9 & 5,4 & 6,4 & 6,9 & 10 & 10 & 9,8 & 7,3 \\
\hline & $\begin{array}{l}\text { Overturning } \\
\text { (left) }\end{array}$ & 5,8 & 9,9 & 5,6 & 9,7 & 1,1 & 5,3 & 5,8 & 4,3 & 5,9 \\
\hline
\end{tabular}

Table 14. Values of comfort index after redesign.

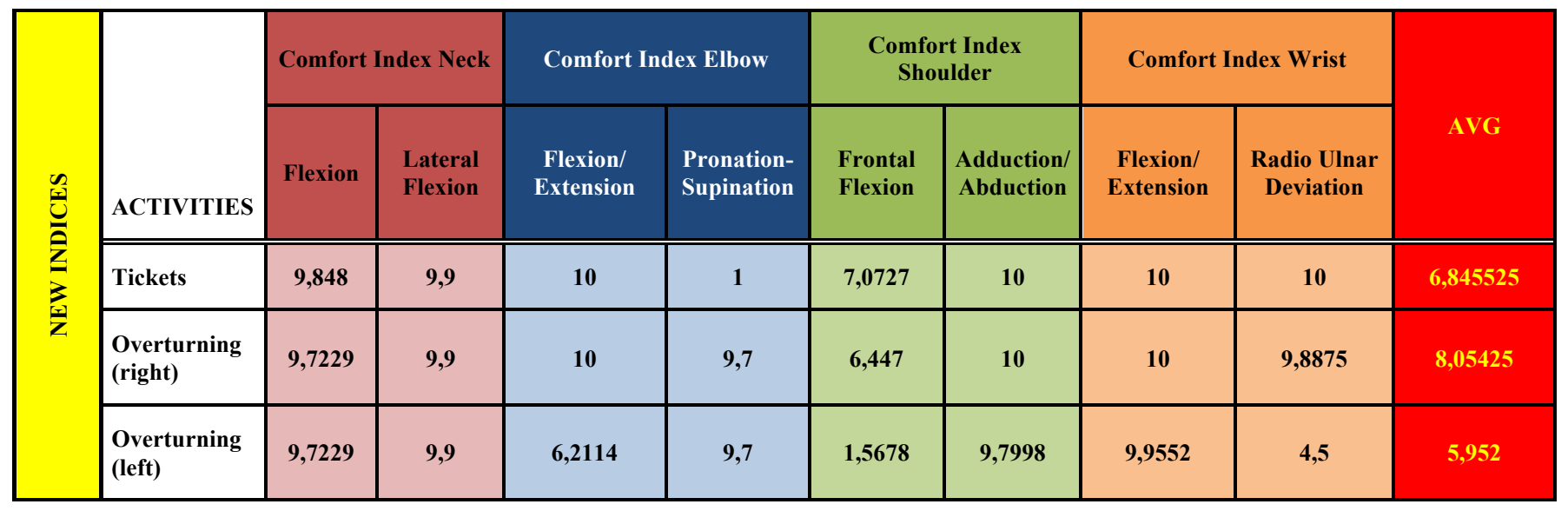


Analyses and evaluations were performed using two of the most popular ergonomics analysis methods: the OCRA Index and the Strain Index, and through a novel comfort evaluation method proposed by University of Salerno (Italy): the $\mathrm{CaMAN}^{\circledR}$ method/software.

Regarding the other activities analyzed, comfort and ergonomics indexes suggested modifications to some angles of the workers' posture in order to improve workers' perceived comfort. These changes need to be combined with training for workers on how to move and use the equipment properly. The described method allowed some issues to be highlighted and some corrections to be proposed. The most important of these are as follows:

The worker has to perform the mattress-taking activity by extending the arm horizontally;

The worker must lift his head in order to have a good visibility, and avoid lowering it;

The worker must avoid very high shoulder abduction;

The worker must avoid very high elbow pronationsupination.

This study shows how a process optimized and redesigned in terms of ergonomics and comfort led to a higher quality working environment and an increase in worker productivity. Additionally, simulating the entire production process with modeling software combined with an analysis of the production flow allowed for the identification of critical processes and for a virtual study (with shorter times and lower costs) of new possibilities for plant lay-out, type and power requirements of the machines, optical warehouse management, and, finally, production organization.

Lastly, it is important to emphasize that the costs to the company for making improvements to a very complex and expensive workstation were in fact low. The estimated cost is $€ .200$, about $€ .125$ for the ergonomic seat and about $€ .75$ pneumatic movement actuator, model SR52.

\section{CONFLICT OF INTEREST}

The authors confirm that this article content has no conflict of interest.

\section{ACKNOWLEDGEMENTS}

Declared none.

\section{REFERENCES}

[1] UNI EN ISO 14738:2009, Safety of Machinery - Anthropometric Requirements for the Design of Workstations at Machinery, 2009.

[2] ISO 11226:2000, Ergonomics - Evaluation of Static Working Postures, 2000.

[3] UNI EN 1005-3:2009, Safety of Machinery - Human Physical Performance - Part3: Recommended Force Limits for Machinery Operation, 2009.

[4] ISO 11228-1, Ergonomics - Manual Handling - Part 1: Lifting and Carrying, 2003.

[5] ISO 11228-2, Ergonomics - Manual Handling - Part 2: Pushing and Pulling, 2007.

[6] ISO 11228-3, Ergonomics - Manual Handling - Part 3: Handling of Low Loads at High Frequency, 2007.
[7] L. McAtamney, and E.N. Corlett, "RULA: a survey method for the investigation of work-related upper limb disorders", Applied Ergonomics, vol. 24, no. 2, pp. 91-99, 1993.

[8] S. Hignett, and L. McAtamney, "Rapid Entire Body Assessment (REBA)", Applied Ergonomics, vol. 31, no. 2, pp. 201-205, 2000.

[9] D. Kee, and W. Karwowski, "LUBA: an assessment technique for postural loading on the upper body based on joint motion discomfort and maximum holding time", Applied Ergonomics, vol. 32, no. 4, pp. 357-366, 2001.

[10] J.S. Moore, and A. Garg, "The strain index: a proposed method to analyze jobs for risk of distal upper extremity disorders", American Industrial Hygiene Association Journal, vol. 56, no. 5, pp. 443-58, 1995.

[11] E. Occhipinti, and D. Colombini, "Proposta di un indice sintetico per la valutazione dell'esposizione a movimenti ripetitivi degli arti superiori (Ocra index)", Medicina del Lavoro, vol. 87, no. 6, pp. 526-548, 1996.

[12] L. Vaentin, A. Gerling, and M. Aptel, "Validité Opérationnelle d'OREGE (Outil de Repérage et d'Evaluation des Gestes)”, Laboratoire de Biomécanique et d'Ergonomie: Département Homme au Travail, Université Henri Poincaré Nancy(FR), 2004.

[13] M. Annarumma, M. Pappalardo, and A. Naddeo, "Methodology development of human task simulation as PLM solution related to OCRA ergonomics analysis", IFIP The International Federation for Information Processing, vol. 277, pp. 19-29, 2008.

[14] C. D'Oria, A. Naddeo, N. Cappetti, and M. Pappalardo, "Postural analysis in HMI design: an extension of OCRA standard to evaluate discomfort level", Journal of Achievements in Materials and Manufacturing Engineering, vol. 39, pp. 60-70, 2010.

[15] T. L. Galinsky, N. G. Swanson, S. L. Sauter, J. J. Hurrell, and L.M. Schleifer, "A field study of supplementary rest breaks for data entry operators", Ergonomics, vol. 43, no. 5, pp. 622-638, 2000.

[16] H. H. Hamberg-van Reenen, A. J. Van der Beek, B. M. Blatter, M. P. Van der Grinten, W. Van Mechelen, and P. M. Bongers, "Does musculoskeletal discomfort at work predict future musculoskeletal pain?", Ergonomics, vol. 51, no. 5, pp. 637-648, 2008.

[17] A. Naddeo, and S. Memoli, "Postural comfort inside a car: development of an innovative model to evaluate the discomfort level", SAE International Journal of Passenger Cars-Mechanical Systems, vol. 2, no. 1, pp. 1065-1070, 2009

[18] M. G. Helander, and L. Zhang, "Field studies of comfort and discomfort in sitting", Ergonomics, vol. 40, no. 9, pp. 895-915, 1997.

[19] M. P. De Looze, L. F. M. Kuijt-Evers, and J. H. Van Dien, "Sitting comfort and discomfort and the relationships with objective measures", Ergonomics, vol. 46, no. 10, pp. 985-997, 2003.

[20] N. C. C. M. Moes, "Analysis of sitting discomfort, a review", In: P.D. Bust, P.T. McCabe, (Eds.), Contemporary Ergonomics; pp. 200-204, 2005.

[21] L. F. M. Kuijt-Evers, L. Groenesteijn, M.P. De Looze, and P. Vink, "Identifying factors of comfort in using hand tools", Applied Ergonomics, vol. 35, no. 5, pp. 453-458, 2004.

[22] E. M. De Korte, M. A. Huysmans, A. M. De Jong, J. G. M. Van de Ven, and M. Ruijsendaal, "Effects of four types of non-obtrusive feedback on computer behavior, task performance and comfort", Applied Ergonomics, vol. 43, no. 2, pp. 344-353, 2012.

[23] P. Vink, and S. Hallbeck, "Editorial: Comfort and discomfort studies demonstrate the need for a new model", Applied Ergonomics, vol. 43, no. 2, pp. 271-276, 2012.

[24] L. Groenesteijn, R. P. Ellegast, K. Keller, F. Krause, H. Berger, and M. P. De Looze, "Office task effects on comfort and body dynamics in five dynamic office chairs", Applied Ergonomics, vol. 43, no. 2, pp. 320-328, 2012.

[25] R. P. Ellegast, K. Keller, L. Groenesteijn, F. Krause, H. Berger, and P. Vink, "Comparison of four specific dynamic office chairs with a conventional office chair: impact upon muscle activation, physical activity and posture", Applied Ergonomics, vol. 43, no. 2, pp. 296307, 2012.

[26] M. M. Franz, A. Durta, R. Zenk, and P. M. A. Desmet, "Comfort effects of a new car headrest with neck support", Applied Ergonomics, vol. 43, no. 2, pp. 336-343, 2012.

[27] Y. U. Kong, D. M. Kim, K. S. Lee, and M. C. Jung, "Comparison of comfort, discomfort, and continuum ratings of force levels and hand regions during gripping exertions", Applied Ergonomics, vol. 43 , no. 2, pp. 283-289, 2012. 
[28] I. Kamp, "The influence of car seat design on its character experience", Applied Ergonomics, vol. 43, no. 2, pp. 3 29-335, 2012.

[29] K. Noro, T. Naruse, R. Lueder, N. Nao, and M. Kozawa, "Application of Zen sitting principles to microscopic surgery seating”, Applied Ergonomics, vol. 43, no. 2, pp. 308-319, 2012.

[30] G. Borg, "Psychophysical bases of perceived exertion", Medicine and Science in Sports and Exercise, vol. 14, no. 5, pp. 377-381, 1982.

[31] D. Kee, and I. Lee, "Relationships between subjective and objective measures in assessing postural stresses", Applied Ergonomics, vol. 43, no. 2, pp. 277-282, 2012.

[32] M. Di Pardo, A. Riccio, F. Sessa, A. Naddeo, and L. Talamo, "Methodology Development for Ergonomic Analysis of Work-Cells in Virtual Environment", SAE Technical Papers, 2008.

[33] R. Zenk, M. Franz, H. Bubb, and P. Vink, "Spine loading in automotive seating", Applied Ergonomics, vol. 43, no. 2, pp. 290295, 2012.

[34] R. Tilley-Alvin, and H. Dreyfuss, "The Measure of Man and Woman: Human Factors in Design", John Wiley \& Sons Inc., USA, 2002.

[35] N. Cappetti, C. D'Oria and A. Naddeo, "New comfort evaluation criteria: application on movie-theatre design" In: Proceedings of the IMProVe, Venezia, Italy, 2011, pp. 01-06.

[36] A. Apostolico, N. Cappetti, C. D'Oria, A. Naddeo, and M. Sestri, "Postural comfort evaluation: experimental identification of range of rest posture for human articular joints", International Journal of Interactive Design and Manufacturing, vol. 8, pp. 109-120, 2014.
[37] M. Fagarasanu, S. Kumar, and Y. Narayan, "Measurement of angular wrist neutral zone and forearm muscle activity", Clinical Biomechanics, vol. 19, no. 7, pp. 671-677, 2004.

[38] H.W. Christensen and N. Nilsson, "The ability to reproduce the neutral zero position of the Head", Journal of Manipulative and Physiological Therapeutics, vol. 22, no. 1, pp. 26-28, 1999.

[39] G. Andreoni, C. Rigotti, G. Baroni, G. Ferrigno, N. A. T. Colford, and A. Pedotti, "Quantitative analysis of neutral body posture in prolonged microgravity”, Gait and Posture, vol. 12, no. 3, pp. 235242, 2000.

[40] E. Mount Frances, M. Whitmore and L. Stealey Sheryl, "Evaluation of Neutral Body Posture on Shuttle Mission STS-57 (SPACEHAB-1)", NASA Technical Reports Server, NASA/TM2003-104805, 2003.

[41] A. Naddeo, N. Cappetti, and O. Ippolito, "Dashboard Reachability and Usability Tests: A Cheap and Effective Method for Drivers' Comfort Rating", SAE Technical Papers, USA, 2014.

[42] A. Naddeo, N. Cappetti, and C. D'Oria, "Proposal of a new quantitative method for postural comfort evaluation", International Journal of Industrial Ergonomics, vol. 48, pp. 25-35, 2015.

[43] D. Colombini, and E. Occhipinti, "The OCRA Method (OCRA Index and Checklist). Updates with special focus on multi-task analysis", W. Karkwoski, and G.S. Ivendy, (Eds.), Applied Human Factors and Ergonomics, Las Vegas, 2008.

[44] A. Naddeo, S. Barba, and I. F. Ferrero Francia, " Propuesta de un nuevo método no invasivo para el análisis postural con aplicaciones de fotogrametría 4d", In: CIBIM , XI Congreso Ibero-Americano de Ingegnieria Mecanica, La Plata: Argentina, 2013, pp. 11-14.

(C) Vallone et al.; Licensee Bentham Open.

This is an open access article licensed under the terms of the Creative Commons Attribution Non-Commercial License (http://creativecommons.org/licenses/by-nc/3.0/) which permits unrestricted, non-commercial use, distribution and reproduction in any medium, provided the work is properly cited. 